\title{
MORFOLOGIA DE FRUTOS, SEMENTES E PLÂNTULAS DE CASTANHEIRA (Terminalia catappa L. - COMBRETACEAE) ${ }^{1}$
}

\author{
SILVIA DE AZEVEDO IVANI ${ }^{2}$, BRENO MARQUES DA SILVAE SILVA 3 , \\ CAMILA DE OLIVEIRA ${ }^{4}$, FABÍOLA VITTI MÔRO
}

RESUMO - O trabalho foi realizado com o objetivo de descrever morfologicamente os frutos, sementes e plântulas de castanheira. Foi feita a biometria dos frutos e das sementes e sua caracterização quanto à forma, por meio de mensurações com paquímetro e observações realizadas em estereomicroscópio com câmara clara. Os frutos de castanheira são carnosos, indeiscentes, do tipo nucóide, glabros, de coloração verde a vinácea, projeção das nervuras carpelares externamente evidentes, com epicarpo delgado, mesocarpo carnoso e esponjoso de coloração vinácea, com feixes vasculares conspícuos em corte transversal. Geralmente, cada fruto contém apenas uma semente. As sementes são exalbuminosas, de formas alongadas e cilíndricas, recobertas por endocarpo rígido de coloração marrom; possuem cerca de $2,5 \mathrm{~cm}, 0,7 \mathrm{~cm}$ e $0,7 \mathrm{~cm}$, de comprimento, largura e espessura, respectivamente. A germinação das sementes de castanheira é epígea, e a plantula é fanerocotiledonar.

Termos para indexação: germinação, reflorestamento, arborização, biometria, chapéu-de-sol.

\section{MORPHOLOGY OF THE FRUIT, THE SEED AND THE SEEDLINGS OF CHESTNUT TREE (Terminalia catappa L. - COMBRETACEAE)}

\begin{abstract}
The work was carried out with the objective of describing morphologically the fruits, seeds and seedlings of chestnut tree. It was made the biometry of the fruits and seeds with a digital pachymeter and its characterization in relation to the shape, in stereomicroscope with clear chamber. It can be evidenced that the chestnut tree fruits are fleshly, indehiscent, nucoid, glabrous, from green to purple coloration, with evident projection of the carpel ribbings, with a fleshly and spongy epicarp and mesocarp, of purple color, with conspicuous vascular bundle in transversal cut. Generally, it has a seed per fruit. The seeds are unalbuminous, of prolongated and cylindrical shape and recovered with a rigid endocarp of brown coloration. The seeds possess about 2,5;0,7 and 0,7 $\mathrm{cm}$, of length, width and thickness, respectively. The germination of the seeds of chestnut tree is epigeal and the seedling is fanerocotyledonary.
\end{abstract}

Index terms: germination, reforestation, arborization, biometry, sun-hat.

\section{INTRODUÇÃO}

Terminalia catappa L., pertencente à família Combretaceae, conhecida popularmente como castanheira, castanhola, castanholeira, chapéu-de-sol e sete-copas, é uma árvore originária da Índia, com cerca de 25 a $45 \mathrm{~m}$ de altura e 50 a $150 \mathrm{~cm}$ de diâmetro, com tronco de retilíneo a tortuoso, crescimento monopodial e ramos de disposição plagiotrópica. As suas folhas são oblanceoladas a obovadas, coriáceas, alternoespiraladas, medindo cerca de 30cm, (Gilman \& Watson, 1994; Ribeiro et al., 1999; Thomson \& Evans, 2006).

Por ser uma espécie rústica e de rápido crescimento, é amplamente utilizada para fins ornamentais (Francis, 1989) e medicinais (Ficarra, 1997; Thomson \& Evans, 2006), de produção de madeira, em reflorestamento, recuperação de áreas degradadas, arborização urbana e rural (Meneses et al., 2003;
Angel et al., 2003).

De acordo com Cavalcante et al. (1986), Gilman \& Watson (1994) e Thomson \& Evans (2006), os frutos e as sementes de castanhola são nutritivas e utilizadas na alimentação humana, assim como de pássaros, morcegos e roedores. Por se alimentarem dos frutos e, às vezes, das sementes, esses animais facilitam a dipersão natural (Penna, 1946; Flores, 2003; Thomson \& Evans, 2006).

As características externas e internas das sementes são pouco modificadas pelo ambiente, constituindo-se um critério bastante seguro para a identificação de famílias, gêneros e, às vezes, espécie (Oliveira \& Pereira, 1984; Groth \& Liberal, 1988). No entanto, poucas publicações são específicas para a identificação e, na maioria delas, a morfologia de sementes é ignorada ou recebe tratamento secundário, sendo, portanto, inadequadas (Gunn, 1981; Oliveira, 1993).

A morfologia interna e a externa da semente, aliada às

'(Trabalho 108-07). Recebido em: 23-04-2007. Aceito para publicação em: 22-11-2007.

${ }^{2}$ Bacharelanda em Ciências Biológicas - Universidade de Franca (UNIFRAN). E-mail: silvia ivani@hotmail.com.

${ }^{3}$ CAPES - Doutorando Agronomia [Produção e Tecnologia de Sementes] - Depto. de Produção Vegetal (DPV) - Faculdade de Ciências Agrárias e Veterinárias (FCAV) - Universidade Estadual Paulista (UNESP Jaboticabal). Depto. de Biologia Aplicada à Agropecuária (DBAA) - FCAV - UNESP Jaboticabal. Via de Acesso Prof. Paulo Donato Castellane s/n, Zona Rural, 14884-900, Jaboticabal - SP - Brasil. E-mail: silvabms@hotmail.com. ${ }^{4}$ Bacharelanda em Ciências Biológicas - Universidade de Franca (UNIFRAN). E-mail: kamilaoliveira@hotmail.com.

${ }^{5} \mathrm{CNPq}$ - Bolsista de Produtividade - Profa. Dra. - Depto. de Biologia Aplicada à Agropecuária (DBAA) - FCAV - UNESP Jaboticabal. Via de Acesso Prof Paulo Donato Castellane s/n, Zona Rural, 14884-900, Jaboticabal - SP - Brasil. E-mail: fabíola@fcav.unesp.br. 
observações das plântulas permitem fazer a identificação de suas estruturas, oferecendo em laboratório subsídios à interpretação correta dos testes de germinação, identificação e certificação da qualidade fisiológica. Assim, pode auxiliar os estudos de armazenamento e, no viveiro, contribuir para o reconhecimento da espécie e para adequar os métodos de produção de mudas (Araújo \& Matos, 1991; Oliveira, 1993; Amorin et al., 1997).

Um dos meios utilizados para determinar o nível de qualidade fisiológica das sementes é o teste-padrão de germinação, o qual é realizado sob condições controladas de temperatura e umidade e em substratos ideais para cada espécie (Gomes \& Bruno, 1992; Zanon et al., 1997). Entretanto, até o momento, não há informações para a avaliação da qualidade fisiológica de sementes de castanheira (Brasil, 1992), assim como para a produção de mudas.

Dessa forma, o presente trabalho teve por objetivo avaliar a germinação e caracterizar morfologicamente o fruto, a semente e a plântula de castanheira.

\section{MATERIAL E MÉTODOS}

Os frutos foram coletados de matrizes de Terminalia catappa L., localizadas no Câmpus da Faculdade de Ciências Agrárias e Veterinárias (FCAV) da Universidade Estadual Paulista (UNESP), localizado em Jaboticabal-SP, Brasil. As descrições morfobiométricas dos frutos e sementes foram realizadas no Laboratório de Morfologia e Anatomia Vegetal - Departamento de Biologia Aplicada à Agropecuária, e a avaliação da germinação, no Laboratporio de Sementes - Departamento de Produção Vegetal da FCAV - UNESP Jaboticabal.

\section{Biometria de frutos, sementes e plântulas}

Para a mensuração dos frutos e sementes, foram utilizadas, respectivamente, 104 e 65 unidades de material fresco, determinando-se o comprimento, largura e espessura, com o auxílio de um paquímetro digital e régua milimetrada. A massa de matéria seca dos frutos e sementes foi obtida por meio da secagem em estufa a $70^{\circ} \mathrm{C}$, durante 72 horas (Benincasa, 2003). Posteriormente, determinou-se o número de sementes $/ \mathrm{kg}$, de acordo com Brasil (1992). Das plântulas, foram obtidas medidas da altura e espessura do colo, bem como determinada a massa de matéria seca, por meio da secagem em estufa a $70^{\circ} \mathrm{C}$, durante 72 horas (Benincasa, 2003).

\section{Morfologia dos frutos e sementes}

Consideraram-se, na caracterização externa, os seguintes aspectos, conforme recomendação de Damião-Filho (1993), Barroso et al. (1999) e Damião-Filho \& Môro (1993): tipo, consistência, superfície, indumentos, forma, deiscência, coloração, ápice, margens e base.

Para o estudo das estruturas internas, foram efetuados cortes longitudinais e transversais nos frutos e sementes, verificando-se: presença ou ausência do endosperma, forma, tipo e posição do embrião.

As observações e as ilustrações das estruturas foram feitas em estereomicroscópio, provido de câmara clara, acompanhada de escala milimétrica. A terminologia adotada para a descrição dos frutos e sementes foi baseada no proposto por Corner (1976), Damião-Filho (1993), Barroso et al. (1999) e DamiãoFilho \& Môro (1993).

\section{Morfologia da plântula}

Para a caracterização da germinação e da plântula, 100 sementes foram semeadas em bandejas de plástico, contendo como substrato areia esterilizada e umedecida com $75 \%$ de sua capacidade de retenção de umidade. Foi adicionada uma solução de Nistatina a $0,2 \%$, visando a conter a proliferação de fungos. A quantidade de água adicionada ao substrato foi calculada com a metodologia descrita pelas Regras de Análise de Sementes (Brasil, 1992). As bandejas foram mantidas em casa de vegetação, sob $25 \%$ de incidência de luz e sem o controle da temperatura e umidade.

Após o início da germinação, o que ocorreu aos 15 dias após a semeadura, foram retiradas, em intervalos regulares em até 30 dias, plântulas representativas de cada fase da germinação e desenhadas com o auxílio de câmara clara, acoplada a um estereomicroscópio. A descrição da plântula foi efetuada segundo Duke (1969) e Ribeiro et al. (1999), e da semente, segundo Corner (1976), Damião-Filho (1993) e Damião-Filho \& Môro (1993).

\section{Determinação do teor de umidade}

Foi adotado o método da estufa a $105^{\circ} \mathrm{C} \pm 3$, durante 24 horas (Brasil, 1992), com 4 repetições de 10 sementes cada.

\section{Avaliação da germinação}

Utilizaram-se quatro tratamentos:

a) frutos inteiros (intactos);

b) frutos sem o epicarpo e o mesocarpo;

c) frutos escarificados (danificados) por morcegos;

d) sementes.

Foram utilizadas cinco repetições com 11 unidades cada, semeadas em bandejas de plástico entre areia lavada e esterilizada, mantidas em casa de vegetação com $25 \%$ de incidência luminosa, em condições ambiente de temperatura média $\left(22,2 \pm 5,06^{\circ} \mathrm{C}\right)$. Os resultados foram obtidos aos 30 dias após a semeadura e expressos em porcentagem de plântulas normais (Brasil, 1992).

\section{6. Índice de velocidade de germinação}

Concomitantemente ao teste de germinação, foram realizadas contagens a cada 7 dias, durante 60 dias, do número de plântulas emersas, ou seja, com a parte aérea acima do substrato. $\mathrm{O}$ cálculo do índice de velocidade de germinação foi realizado conforme a equação proposta por Maguire (1962).

O delineamento experimental adotado foi o inteiramente casualizado, e para avaliação da variância e comparação das médias, os dados em porcentagem foram transformados em arc-

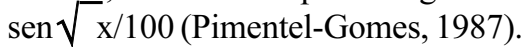




\section{RESULTADOS E DISCUSSÃO}

\section{Morfologia dos frutos e sementes}

\section{Morfologia dos frutos}

Os frutos de castanheira são carnosos, indeiscente, drupáceos (nucóides), como citado por Barroso et al. (1999), glabros, de coloração verde a vinácea, com a projeção das nervuras carpelares evidentes, portando, em geral, uma semente e, raramente, duas, medindo cerca de $5,51 \pm 0,48 \mathrm{~cm}, 3,99 \pm 0,44 \mathrm{~cm}$ e $3,12 \pm 0,46 \mathrm{~cm}$, de comprimento, largura e espessura, respectivamente (Figura 1). Para o volume, massa seca e número de frutos por quilograma, foram observadas médias de $70 \pm$ $21,28 \mathrm{~cm}^{3}, 7,76 \pm 1,25 \mathrm{~g}$ e $304,84 \pm 9,10$ frutos $/ \mathrm{kg}$, respectivamente. No entanto, os frutos apresentaram comprimento, largura, espessura, massa de matéria seca e volume máximos e mínimos entre 3,35 e $6,57 \mathrm{~cm}, 2,81$ e $5,24 \mathrm{~cm}, 2,32$ e $4,31 \mathrm{~cm}, 5,24$ e 10,69g, 35,06 e $127,16 \mathrm{~cm}^{3}$, respectivamente (Figura 2). De acordo com Silva \& Valente (2005), as combretáceas são exalbuminosas e com cotilédones convolutos ou plicados.

Nos frutos, o pericarpo de castanheira é constituído por um epicarpo, delgado, levemente esponjoso e de coloração vinácea, um mesocarpo, carnoso, esponjoso e fibroso, vináceo, com presença nítida de seis feixes vasculares distribuídos ao longo do maior eixo dos frutos, e um endocarpo, espesso, lenhoso, de coloração creme a marron, com visível linha de fissura longitudinal (Figura 1B).

\section{Morfologia externa das sementes}

As sementes de castanheira são exalbuminosas, cônicas, alongadas e levemente achatadas, de coloração amarela a ocre, levemente rugosa, com funículo persistente, medindo cerca de $2,49 \pm 0,21 \mathrm{~cm}$ e $0,75 \pm 0,08 \mathrm{~cm}$, de comprimento e largura, respectivamente (Figura 3A). O tegumento é delgado, glabro, com hilo circular, homócromo, localizado na base da semente, sendo que a calaza é marcada por uma mancha de coloração marrom, no ápice da semente, a rafe é de cor marrom e estendida entre o hilo e a calaza. A micrópila é inconspícua (Figura 3). De forma semelhante, Ferreira et al. (1998) descreveram para as sementes de Terminalia argentea Mart. \& Zucc.

Para o volume, massa seca, teor de água e número de sementes por quilograma de castanheira, foram observadas médias de $1,42 \pm 0,33 \mathrm{~cm}^{3}, 0,1657 \pm 0,09 \mathrm{~g}, 31.27 \pm 8,35 \%$ e 1934,24 $\pm 364,95$ sementes $/ \mathrm{kg}$, respectivamente. As sementes de Terminalia catappa L. apresentaram comprimento e largura, volume e matéria seca máximos e mínimos entre 1,96 e 3,01 cm, 0,59 e $0,95 \mathrm{~cm}, 0,82$ e $2,30 \mathrm{~cm}^{3}$ e 0.0590 e $0.2705 \mathrm{~g}$, respectivamente (Figura 4).

\section{Morfologia interna das sementes}

O embrião das sementes de castanheira é axial, com cotilédones convolutos e foliáceos, brancos, e eixo radicular proeminente. Enquanto o eixo embrionário é curto, reto, cilíndrico, com plúmula rudimentar e quase totalmente envolvido pelos cotilédones (Figura 3).

\section{Morfologia da plântula aos 30 dias após a semeadura}

O desenvolvimento pós-seminal de castanheira é marcado pelo rompimento do tegumento da semente pela protrusão da raiz primária, cilíndrica, glabra e de coloração branca a amarelada e, em seguida, a formação de raízes secundárias filiformes. Posteriormente, ocorre o crescimento pronunciado do hipocótilo cilíndrico de coloração verde, elevando os cotilédones com a plúmula (Figura 5).

Os cotilédones são opostos, foliáceos, reniformes, com base reniforme, bordo inteiro, longo-peciolados e com venação eucampdódroma (Francis, 1989). Na base do limbo, o pecíolo é canaliculado, enquanto na outra extremidade é cilíndrico, com tricomas simples, esparsos e esbranquiçados. Concomitantemente, é visível o desenvolvimento de raízes terciárias, de coloração branca, com tricomas simples e hialinos (Figura 5).

A região do coleto é evidente pela diferença de coloração e espessura entre o hipocótilo e a raiz. Com o crescimento da plântula, essa região adquire forma característica, descrita para capitão-de-sol por Ferreira et al. (1998) como em forma de "joelho" (Figura 5).

Em seguida, ocorre o crescimento do epicótilo, cilíndrico, verde, com tricomas simples, longos e esbranquiçados, e com eófilos, simples, alternos, com margem inteira e de coloração verde a ferrugínea, com tricomas na face adaxial e abaxial. A nervação é peninérvea, levemente proeminente na face adaxial e, marcadamente, na face abaxial (Figura 5). De forma semelhante, foram ilustradas as folhas de Terminalia catappa L. por Flores (2003).

\section{Avaliação da germinação}

Os maiores valores tanto para a porcentagem quanto para o índice de velocidade de germinação foram obtidos para o tratamento em que se usaram apenas sementes de castanheira (Tabela 1). Desta forma, observou-se que o pericarpo do fruto, apesar de servir como atrativo para os dispersores (Penna, 1946; Flores, 2003; Thomson \& Evans, 2006), torna-se uma barreira mecânica para a germinação das sementes de castanheira.

Em contrapartida, quando os frutos foram escarificados por morcegos ou manualmente, as porcentagens de germinação das sementes foram elevadas e semelhantes entre si quando comparadas com os frutos inteiros (Tabela 1).

Os dipersores da castanheira, em especial os morcegos, provavelmente Artibeus cf. fimbriatus Gray, 1838 (Mammalia, Chiroptera, Phyllostomidae), auxiliam tanto na dispersão quanto no processo germinativo, pois, consumindo o epicarpo e o mesocarpo dos frutos, provavelmente promovem a escarificação parcial do pericarpo, o que influencia de maneira positiva na germinação das sementes (Tabela 1). 
TABELA 1 -Teor de água, porcentagem e índice de velocidade de germinação de sementes e sementes contidas em frutos inteiros (FI), em frutos escarificados por morcegos (FEM), frutos escarificados manualmente (FEA) de Terminalia catappa $\mathrm{L}$.

\begin{tabular}{|c|c|c|c|c|}
\hline \multirow[t]{2}{*}{ Parâmetros } & \multicolumn{4}{|c|}{ Teor de água (\%) } \\
\hline & FI & FEM & FEA & Sementes \\
\hline \multirow{4}{*}{ Tratamentos } & $30.56 \pm 8.35$ & $24.52 \pm 6.12$ & $30.56 \pm 8,35$ & $30.56 \pm 8,35$ \\
\hline & \multicolumn{4}{|c|}{ Germinação (\%) } \\
\hline & FI & FEM & FEA & Sementes \\
\hline & $9.09 \mathrm{C}$ & $43.63 \mathrm{~B}$ & $41.81 \mathrm{~B}$ & $69.09 \mathrm{~A}$ \\
\hline DMS & \multicolumn{4}{|c|}{12.4883} \\
\hline CV (\%) & \multicolumn{4}{|c|}{16.85} \\
\hline Parâmetros & \multicolumn{4}{|c|}{ Índice de velocidade de germinação } \\
\hline \multirow{2}{*}{ Tratamentos } & FI & FEM & FEA & Sementes \\
\hline & $0.0172 \mathrm{C}$ & $0.0756 \mathrm{BC}$ & $0.1015 \mathrm{~B}$ & $0.2030 \mathrm{~A}$ \\
\hline DMS & \multicolumn{4}{|c|}{0.0664} \\
\hline $\mathrm{CV}(\%)$ & \multicolumn{4}{|c|}{36.90} \\
\hline
\end{tabular}
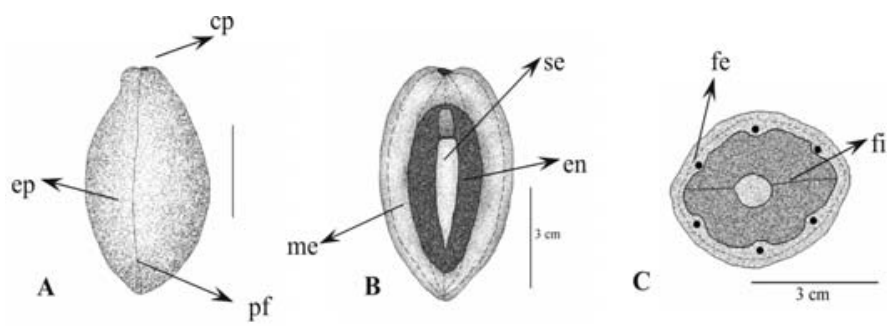

FIGURA 1- A) Vista lateral do fruto de Terminalia cattapa L.; B) Corte longitudinal do fruto; C) Corte transversal do fruto. (cp - cicatriz do pedúnculo; ep - epicarpo; pf - proeminência da fissura; me mesocarpo; en -endocarpo; se - semente; fi fissura; fe - feixe vascular). Barra $-3 \mathrm{~cm}$.

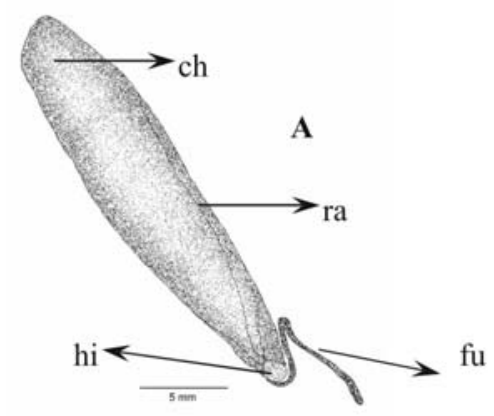

FIGURA 3 - A) Vista frontal da semente de Terminalia catappa L.; B) Embrião e eixo embrionário da semente de Terminalia catappa. (ch - calaza; ra - rafe; fu - funículo; hi - hilo; te - tegumento; cc - cotilédone; ee - eixo embrionário). Barra - embrião $-2 \mathrm{~mm}$. Barra - semente $-5 \mathrm{~mm}$.
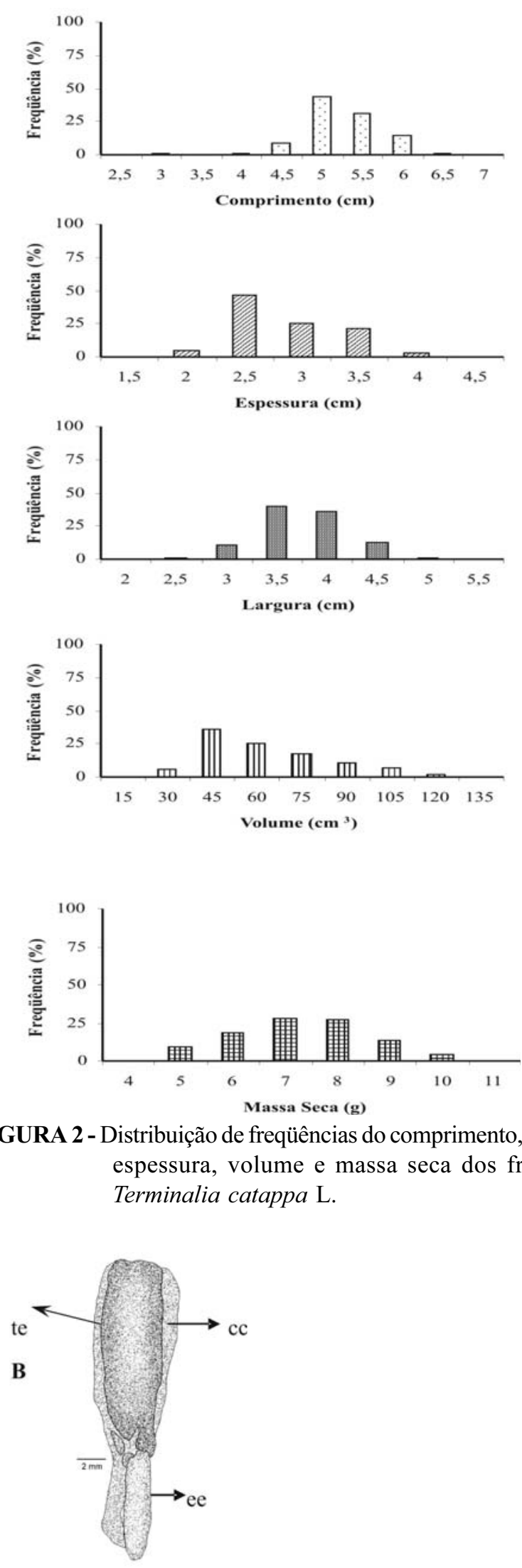

FIGURA 2 - Distribuição de freqüências do comprimento, largura, espessura, volume e massa seca dos frutos de Terminalia catappa L. 

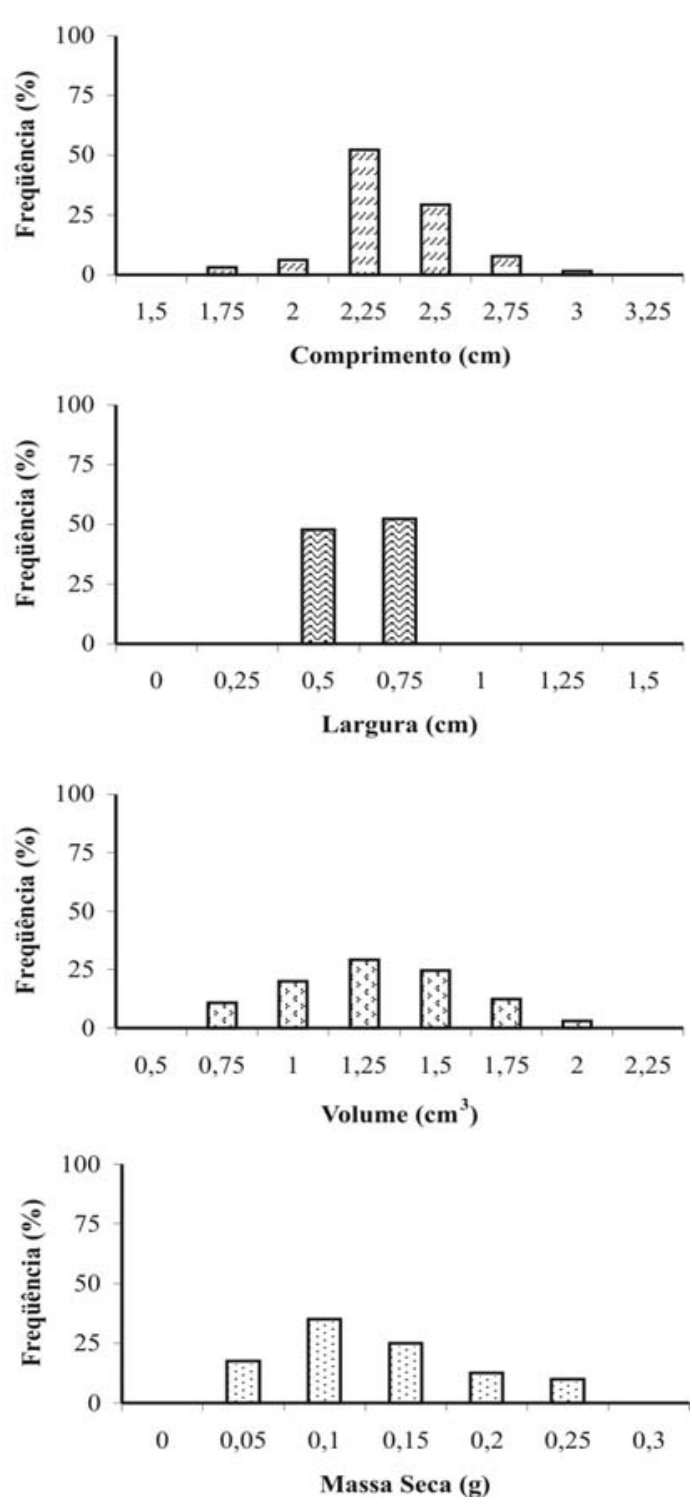

FIGURA 4-Distribuição de freqüências do comprimento, largura, massa seca e volume das sementes de Terminalia catappa $\mathrm{L}$.
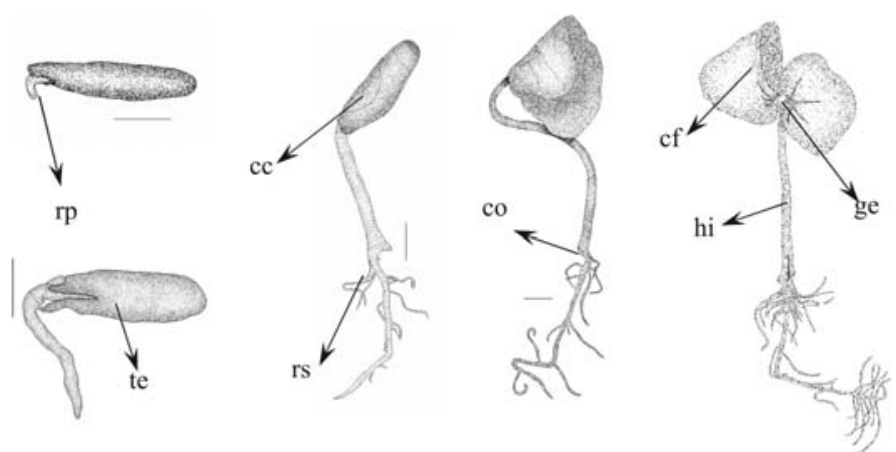

FIGURA 5 - Estádios sucessivos do desenvolvimento da plântula de Terminalia catappa L. ( $\mathrm{rp}$ - raiz primária; te tegumento; cc - cotilédone; rs - raiz secundária; co - coleto; $\mathrm{cf}$ - cotilédone foliáceo; ge - gema apical; hi-hipocótilo). Barra-1cm.

\section{AGRADECIMENTOS}

À Universidade Estadual Paulista-UNESP Jaboticabal, pela estrutura e materiais necessários para a realização do trabalho. Ao Sr. Lázaro R. da Silva, pela colaboração durante a condução do experimento.

\section{REFERÊNCIAS}

AMORIM, I. L.; DADIVE, A. C.; CHAVES, M. M. F. Morfologia do fruto e da semente, e germinação da semente de Trema micrantha (L.) Blum. Cerne, Lavras, v. 3, n. 1, p. 138-152, 1997.

ANGEL, M.H.; BACALLAO, L.G.; DOMINGUEZ, D.M.R.; PADILLA, D.O. Almendro de La índia: potencial biológico valioso. Revista Cubana Investigación Biomédica, Las Habana, v. 22, n. 1, p. 41-7. 2003.

ARAÚJO, S. S.; MATOS, V. P. Morfologia da semente e de plântulas de Cassia fistula L. Revista Árvore, Viçosa, v. 15, n. 3, p. 217-223. 1991

BARROSO, G.M.; MORIN, M.P.; PEIXOTO, A.L.; ICHASO,C.L.F. Frutos e sementes: morfologia aplicada à sistemática de dicotiledôneas. Viçosa: UFV, 1999. 443p.

BENINCASA, M.M.P. Análise de crescimento de plantas: noções básicas. Jaboticabal: FUNEP, 2003.41p.

BRASIL. Ministério da Agricultura e Reforma Agrária. Regras para análise de sementes. Brasília, 1992.365 p.

CAVALCANTE, M.A.; MAIA, G.A.; FIGUEIREDO, R.W.; TEIXEIRA, V.A.M. Características físicas químicas da Castanhola, Terminalia catappa L. Ciência Agronômica, Fortaleza, v. 17, n. 1, p. 111-116, 1986.

CORNER, E.J.H. The seeds of dicotyledons. Cambrige: University, Press, 1976. v.1,311p.

DAMIÃO-FILHO, C.F; MÔRO, F.V. Morfologia externa das espermatófitas. In: DAMIÃO-FILHO, C.F. Morfologia e anatomia de sementes. Jaboticabal - SP: FCAV/UNESP, 1993. 145p. Apostila da Disciplina do Curso Pós-graduação Morfologia e Anatomia de Sementes.

DUKE, J.A. On tropical tree seedlings. Seed, seedlings, systems and systematics. Annals of Missouri Botanical Gardens, St. Louis, v.56, n.2, p.125-161, 1969.

FERREIRA, R.A.; BOTELHO, S.A.; MALAVASI, M.M.; DAVIDE, A.C. Caracterização de fruto, semente, plântula e muda de Capitão-doCampo (Terminalia argentea Mart. \& Zucc. Combretaceae). Revista Brasileira de Sementes, Pelotas, v. 20, n. 2, p. 202-209-1998. 
FICARRA, R. Isolation and characterization of Guiera senegalensis J. F. Gmel. Active principles. Bolletino Chimico Farmceutico, Milano, v. 136, n. 5, p. 454-459. 1997.

FLORES, E.M. Terminalia catappa L.: tropical tree seed manual. Species Descriptions, 2003. 2p. Disponível em: $<\mathrm{http}: / /$ www.rngr.net/Publications/ttsm/Folder.2003-07-11.4726/ PDF.2004-03-16.0017/file>.

FRANCIS, J.K. Terminalia catappa L: indian almond, almendra. Rio Piedras: Institute of Tropical Forestry. 1989. (SO-ITF-SM23).

GILMAN, E.F.; WATSON, D.G.. Terminalia catappa tropicalalmond. Gainsville: Institute of Food and Agricultural Sciences, University of Florida, 1994.3p

GOMES, S.M.S.; BRUNO, R.L.A. Influência da temperatura e substratos na germinação de sementes de urucum (Bixa orellana L.). Revista Brasileira de Sementes, Brasilia, v. 14, n. 1, p. 47-50. 1992.

GROTH, D.; LIBERAL, O.H.T. Catálogo de identificação de sementes. Campinas: Fundação Cargil, 182p. 1988.

GUNN, C.R. Seed topography in the Fabaceae. Seed Science \& Technology, Zurich, n. 9, p. 737-757. 1981.

MAGUIRE, J.D. Speed of germination-aid seedling emergence and vigor. Crop Science, Madison, v.2, n.1, p.176-177, 1962.

MENESES, C.H.S.G; SOUSA, E.B.M.; MEDEIROS, F.P.M.; MENEZES, I.R.; ALBUQUERQUE, H.N.; SANTOS, L. Análise da arborização dos bairros do Mirante e Vila Cabral na cidade de Campina Grande - PB. Revista de Biologia e Ciências da Terra, Paraíba, v. 3, n. 2, p. 120-126. 2003.
OLIVEIRA, E. C.; PEREIRA, T.S. Morfologia dos frutos alados em Leguminosae-Caesalpinioideae-Martiodendron Gleason, Peltophorum (Vogel) Walpers, Sclerolobium Vogel, Tachigalia aublet e Schizolobium Vogel. Rodriguesia, Rio de Janeiro, v.36, n. 60, p. 35-42. 1984.

OLIVEIRA, E.C. Morfologia de plântulas florestais. In: AGUIAR, I.B.; PIÑA-RODRIGUEZ, F.C.M. \& FIGLIOLA, M.B. Sementes florestais tropicais. Brasília: ABRATES, 1993. p.175-214.

PENNA, M. Dicionário brasileiro de plantas medicinais. Rio de Janeiro: Kosmos, 1946. 409p.

PIMENTEL-GOMES, F. Curso de estatística experimental. São Paulo: Nobel, 1987.467p.

RIBEIRO, J.E.L.S.; HOPKINS, M.J.G; VICENTINI, A.; SOTHERS, C.A.; COSTA, M.A.S.; BRITO, J.M.; SOUZA, M.A.D.; MARTINS, L.H.P.; LOHMANN, L.G.; ASSUNÇÃO, P.A.C.; PEREIRA, E.C.; SILVA, C.F.; MESQUITA, M.R.; PROCÓPIO, L.C. Flora da reserva ducke: guia de identificação das plantas vasculares de uma floresta de terra-firma na Amazônia Central. Manuas: INPA, 1999. 816p.

SILVA, M.N.F.; VALENTE, M.C.. Flora da Reserva Ducke, Amazonas, Brasil: Combretaceae. Rodriguésia, Rio de Janeiro, v. 56, n. 86, p. 131-140. 2005.

THOMSON, L.A.J.; EVANS, B. Terminalia catappa (tropical almond), ver. 2.2. In: ELEVITCH, C.R. (Ed.). Species profiles for pacific Island agroforestry: permanent agriculture resources (PAR), 2006. Disponível em: <http://www.traditionaltree.org $>$.

ZANON, A.; CARPANEZZI, A.A.; FOWLER, J.A.P. Germinação em laboratório e armazenamento de sementes de Tarumã-Branco (Citharexylum myrianthum CHAM.). Boletim de Pesquisa Florestal, Colombo, n. 35, p.75-82. 1997. 